\title{
The response of African land surface phenology to large scale climate oscillations
}

\author{
Molly E. Brown ${ }^{\mathrm{a}, *}$, Kirsten de Beurs ${ }^{\mathrm{b}}$, Anton Vrieling ${ }^{\mathrm{c}}$ \\ a Biospheric Sciences Branch, NASA Goddard Space Flight Center, Greenbelt, MD 20771, United States \\ b Virginia Polytechnic Institute and State University, Department of Geography, 115 Major Williams Hall, Blacksburg, VA 24061, United States \\ ' University of Twente, Faculty of Geo-Information Science and Earth Observation, P.O. Box 6, 7500 AA Enschede, The Netherlands
}

\section{A R T I C L E I N F O}

Article history:

Received 19 March 2009

Received in revised form 29 April 2010

Accepted 2 May 2010

\section{Keywords:}

AVHRR NDVI

ENSO

NAO

PDO

Start of season

Agriculture

\begin{abstract}
A B S T R A C T
Variations in agricultural production due to rainfall and temperature fluctuations are a primary cause of food insecurity on the African continent. Analysis of changes in phenology can provide quantitative information on the effect of climate variability on growing seasons in agricultural regions. Using a robust statistical methodology, we describe the relationship between phenology metrics derived from the 26 year AVHRR NDVI record and the North Atlantic Oscillation index (NAO), the Indian Ocean Dipole (IOD), the Pacific Decadal Oscillation (PDO), and the Multivariate ENSO Index (MEI). We map the most significant positive and negative correlation for the four climate indices in Eastern, Western and Southern Africa between two phenological metrics and the climate indices. Our objective is to provide evidence of whether climate variability captured in the four indices has had a significant impact on the vegetative productivity of Africa during the past quarter century. We found that the start of season and cumulative NDVI were significantly affected by large scale variations in climate. The particular climate index and the timing showing highest correlation depended heavily on the region examined. In Western Africa the cumulative NDVI correlates with PDO in September-November. In Eastern Africa the start of the June-October season strongly correlates with PDO in March-May, while the PDO in December-February correlates with the start of the FebruaryJune season. The cumulative NDVI over this last season relates to the MEI of March-May. For Southern Africa, high correlations exist between SOS and NAO of September-November, and cumulative NDVI and MEI of March-May. The research shows that climate indices can be used to anticipate late start and variable vigor in the growing season of sensitive agricultural regions in Africa.
\end{abstract}

Published by Elsevier Inc.

\section{Introduction}

Satellite remote sensing has become a primary input to programs that monitor food production in Africa. Small scale, rainfed agriculture is a primary occupation and source of food for many rural residents (Alberts \& Mehta, 2004; Breman, 2003). Hundreds of millions of Africans rely on sufficient rainfall and moderate temperatures in order to produce enough food to feed their families (FAO, 2006). Global trends in climate are increasingly impacting rainfall and temperature (Parry et al., 2007), which may ultimately reduce the ability of Africans to grow their own food (USAID, 2007).

Here we explore the relationship between phenological metrics derived from vegetation index data and four common climate indices to determine which most influences local growing conditions in SubSaharan Africa. Our objective is to identify the seasonal periods when large sale climate oscillations influenced observed land surface phenology during the past 26 years at the regional level using

\footnotetext{
* Corresponding author.

E-mail address: molly.brown@nasa.gov (M.E. Brown).
}

vegetation index measurements of the start of the growing season and its productivity.

As population increases and food supplies become more constrained, the need to monitor agricultural production even in the least productive regions will grow (Funk \& Brown, 2009; Funk \& Budde, 2009). The amount of food produced locally often interacts with global commodity prices to determine the price of food on the market, affecting the ability of millions of poor urban and rural Africans to access food (Brown et al., 2006). The stability of governments and regions often are disrupted when there is a widespread lack of access and increasing hunger due to rising food prices (FEWS, 2008; Vasagar, 2005). Quantitative understanding of the connection between growing season dynamics and climate indices could improve the ability of monitoring organizations to forewarn widespread agricultural production deficits.

Vegetation index data are often used by agencies monitoring agricultural conditions to assess and predict agricultural production and identify periods of weather-related production declines (Brown, 2008). Vegetation and rainfall data have become the basis for operational monitoring of agricultural production, assessing variables such as the start of season, growing season length and overall growing season productivity (Brown, 2008; Brown \& de Beurs, 2008). 
Phenology metrics have a strong relationship with regional food production, particularly those with sufficiently long records to capture local variability (Vrieling et al., 2008). Previous authors have used the long term climate data record from the AVHRR instruments on the NOAA satellites as an environmental observational record which may be directly related to climate variations (Anyamba, 1997; Verdin et al., 1999).

Climate indices are used to reflect the essential elements of climate and its fluctuations through time. ENSO (El Niño Southern Oscillation) is the best known index of climatic variability, but others also express interannual climatic variability in Africa. Here we use the North Atlantic Oscillation index (NAO), the Indian Ocean Dipole (IOD), the Pacific Decadal Oscillation (PDO), and the Multivariate ENSO Index (MEI). Each of these has been explored independently in the literature as to their impact on the African climate (Anyamba et al., 2001; Green \& Hay, 2002; Jury et al., 1994; Rasmussen, 1991; Verdin et al., 1999; Wang, 2003). Strong negative ENSO or MEI anomalies are associated with an "El Niño" event (Cane et al., 1996) and strong positive departures of the index are associated with "La Niña" conditions (Rasmusson \& Wallace, 1983). Warm ENSO events are characterized by above normal Sea Surface Temperatures (SSTs) in the eastern Pacific and sometimes above normal SSTs in the western Indian Ocean, as described by the IOD. Warm ENSO events, documented in the MEI, are known to increase precipitation in some regions of Eastern Africa and result in droughts in southern Africa (Glantz et al., 1991; Ropelewski \& Halpert, 1987). The Pacific Decadal Oscillation tends to increase the drought effects of warm ENSO events (Woodward et al., 2008), and interacts with the Atlantic Decadal Oscillation to augment or weaken rainfall response (McCabe et al., 2004) and thus could be an important influence on productivity in Africa (Williams et al., 2008).

By examining the spatial distribution and interaction of these effects, we can determine which indices are most important in each region for productivity (Zhang et al., 2005). We provide maps of regions that have an earlier growing season start and a higher than normal growing season length and amplitude and regions with later than normal start and lower seasonal amplitude. By conducting an analysis with many climate indicators and multiple phenological metrics, we intend to cast a broad enough net to provide guidance for data analysts who at present are focusing solely on one metric in exclusion of others.

\section{Data}

\subsection{Normalized difference vegetation index data}

We used maximum value AVHRR 15-day NDVI composites (Holben, 1986) from the NASA Global Inventory Monitoring and Modeling Systems (GIMMS) group at NASA's Biospheric Sciences Branch from July 1981 to December 2008 (Tucker et al., 2005). A postprocessing satellite drift correction has been applied to this dataset to further remove artifacts due to orbital drift and changes in the suntarget-sensor geometry (Pinzon et al., 2005). The GIMMS operational dataset incorporates data from sensors aboard NOAA-7 through 14 with the data from the AVHRR on NOAA-16 and 17 using SPOT data as a bridge for a by-pixel inter-calibration. 7Details of this calibration can be found in (Tucker et al., 2005). Pixels with flags of 2-6 were removed from the analysis.

\subsection{Climate indices}

We used four indices of global climate variations based on variations in atmospheric pressure and sea surface temperatures from various regions. These are the North Atlantic Oscillation index (NAO), the Indian Ocean Dipole (IOD), the Pacific Decadal Oscillation
(PDO), the Multivariate ENSO Index (MEI). We used the following indices:

- NAO: ftp://ftp.cpc.ncep.noaa.gov/wd52dg/data/indices/tele_index.nh

- IOD: http://www.jamstec.go.jp/frsgc/research/d1/iod/

- PDO: http://jisao.washington.edu/pdo/PDO.latest

- MEI: http://www.cdc.noaa.gov/ClimateIndices/

Fig. 1 gives an overview of the variability of the indices over the past 26 years.

A mode of climate variability with extensive effects in the Northern Hemisphere, is the Northern Annular Mode (NAM; (Thompson \& Wallace, 2001)), which also goes by the name of the North Atlantic Oscillation (NAO; (Hurrell, 1995)). The North Atlantic Oscillation (NAO) index is typically measured through variations in the normal pattern of lower atmospheric pressure over Iceland and higher pressure near the Azores and Iberian Peninsula (Jones et al., 1997). A positive NAO index refers to an increased difference in pressure between these two regions and thus stronger westerly winds. This corresponds to a stronger storm track across the Atlantic from Western Africa. The negative mode of the NAO-when there is less difference than usual in pressure across the two regions-features a weakened Atlantic storm track. The NAO trended toward more positive values from the 1960s to the mid-1990s, but has since returned to more normal values (UCAR, 2009).

The Indian Ocean Dipole (IOD) is an interannual (year-to-year) climate pattern across the tropical Indian Ocean first identified in 1999 (Saji et al., 1999). In the positive phase of the IOD, trade winds are stronger than usual and cooler-than-average sea surface temperatures are prevalent across the eastern tropical Indian Ocean, near Indonesia and Australia. To the west, near Madagascar, waters are warmer than average and convection is intensified, thus causing heavy rainfall in Eastern parts of Africa. These patterns are reversed during the IOD's negative phase (UCAR, 2009).

The Pacific Decadal Oscillation (PDO) is a multidecadal pattern of climate variability centered across the North Pacific Ocean (Mantua et al., 1997). During the positive (warm) phase of the PDO, sea surface temperatures tend to be above average along the west coast of North America and in the eastern tropical Pacific; while across the central North Pacific they are cooler than average. The opposite patterns occur during the negative (cool) phase. The PDO may be related to ENSO, but differs mainly because the timescale for the PDO is much longer (several decades) and because the PDO more clearly involves the extratropical Pacific and the Aleutian low pressure system (UCAR, 2009). Although the PDO has a longer cycle than ENSO, it shows sufficient interannual variability to correlate with observed variations in productivity in Africa. The impact of the PDO on the climate of Africa during the past few decades is unclear, although studies suggest a correlation with rainfall in Eastern and Southern Africa (Mantua \& Hare, 2002).

The Multivariate ENSO Index (MEI) is a measure of the comparative strength of El Nino Southern Oscillation (ENSO) events (Wolter \& Timlin, 1998). It is derived by combining several different indices that separately measure weather variables in the tropical Pacific, such as sea surface temperature, sea-level pressure (SOI), surface winds, surface air temperature, cloudiness, precipitation, and other variables (UCAR, 2009).

\section{Methods}

\subsection{NDVI processing}

The NDVI data were temporally filtered and phenology parameters were extracted in order to estimate the potential impact of the climate indices on growing season variability in the region and consequently on food production. The 15-day GIMMS data was found to be adequate for this analysis, as the daily data in the AVHRR data is 

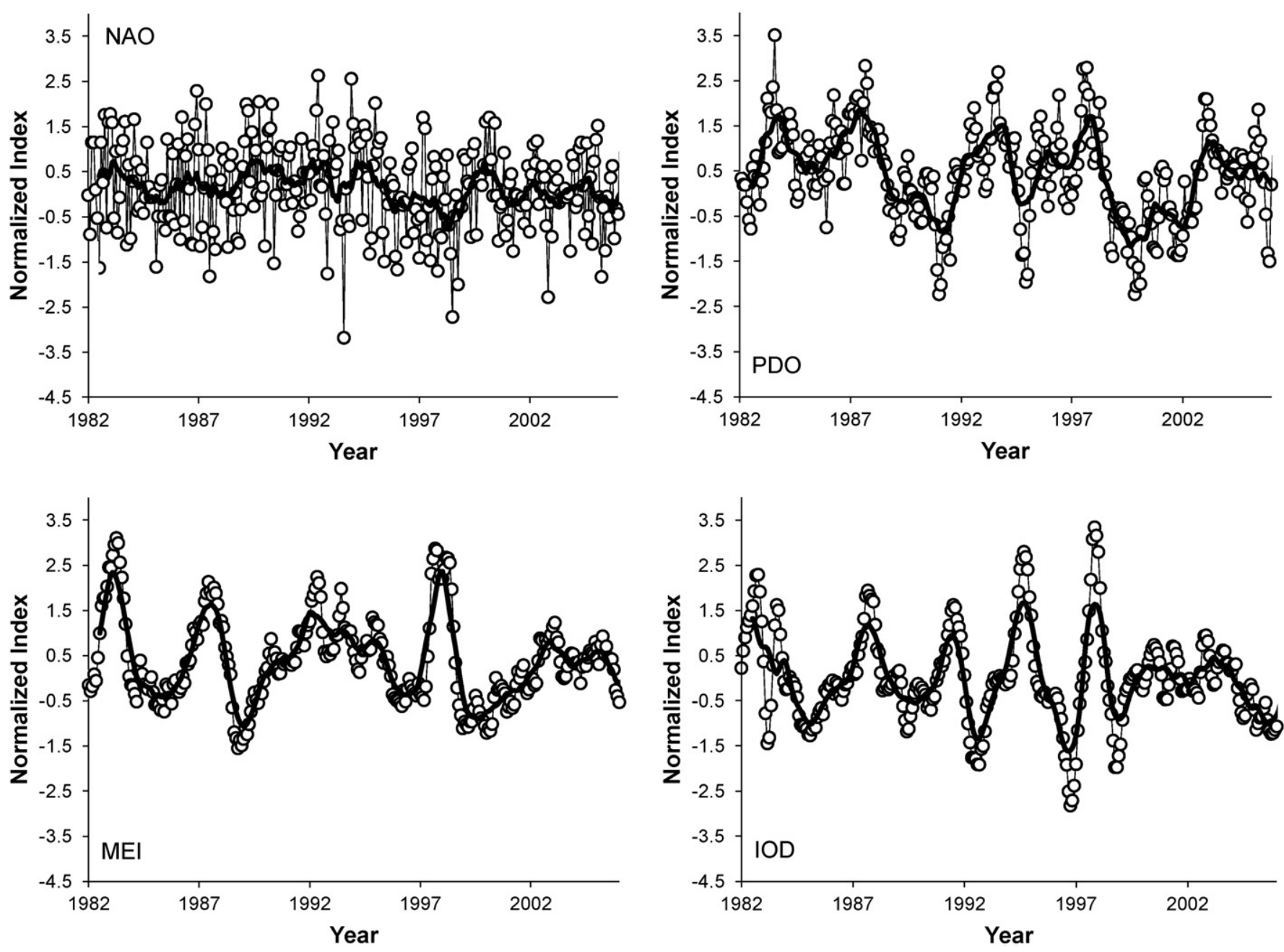

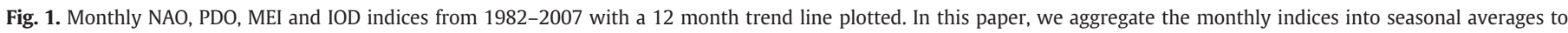
correlate with phenology metrics.

very noisy and contaminated with clouds. To create smoothed daily data for the phenology model and to reduce any remaining cloud effect in the NDVI data, temporal filtering was performed by means of an iterative Savitzky-Golay filter (Chen et al., 2004; Vrieling et al., 2008). The method interpolates the 15-day observations to create estimated daily values for use in the phenological model. Three regions were analyzed, Eastern Africa, Western Africa and Southern Africa (Fig. 2).

\subsection{Phenological analysis}

The simplest and perhaps most often applied method to determine the start of season is based on artificially set threshold values defined in 1 ) units of NDVI; 2 ) the $50 \%$ point of the green up; or 3 ) the crossing of the smoothed data with an autoregressive moving average mode (de Beurs and Henebry, 2010). Here, we used the percent threshold or mid-point NDVI method proposed by (White et al., 1997) to extract annual phenological metrics. The onset and conclusion of the growing season are estimated using NDVI curves, extracting for each pixel and year the start of season (SOS), and end of season (EOS) as the timing of the crossing of the $50 \%$ point of the NDVI curve in upward or downward direction respectively. Since the African growing seasons do not consistently fall within one calendar year, we determined SOS and cumulative NDVI based on two different time periods both incorporating 1.5 years of data: cycle 1 : October year 1 - March year 3 and cycle 2: April year 2 - October year 3 (Fig. 3). These time frames allow for the estimation of growing seasons in both the Northern
Hemispheric and the Southern Hemispheric parts of Africa. In addition, it allows for the detection of double cropped regions such as can be found in Eastern Africa. Additional information on growing season dynamics in Africa can be found in the literature in a variety of disciplines (Ellsworth \& Shapiro, 1989; Justice et al., 1985; Lotsch et al., 2003; Sacks et al., in press; Verdin et al., 1999).

Two phenology metrics were considered for this analysis, although five were calculated in the model. The model determines the start of season (SOS), end of season (EOS), length of season (LOS), the maximum NDVI of the season (maxNDVI), and the cumulated NDVI over the season (cumNDVI). The extraction of these parameters is straightforward based on SOS, EOS, and the filtered time series (Fig. 4). The length of season (LOS) parameter is calculated as LOS $=$ EOS - SOS. We defined that LOS should be at least a month to be valid, and before calculating other metrics. In this paper, we report findings on the SOS and the cumulative NDVI as the most meaningful across the diverse ecosystems. Variation in SOS in Western Africa due to sowing delays can translate into yield reductions (Buerkert et al., 2001) while cumulative NDVI is indicative of net primary productivity (Awaya et al., 2004).

\subsection{Climate correlation}

The two phenology metrics described above were correlated to the four climate indices NAO, PDO, MEI and IOD. To reduce noise and increase the signal for each climate index, we aggregated the monthly climate indices into four seasons to determine the correlation with the 


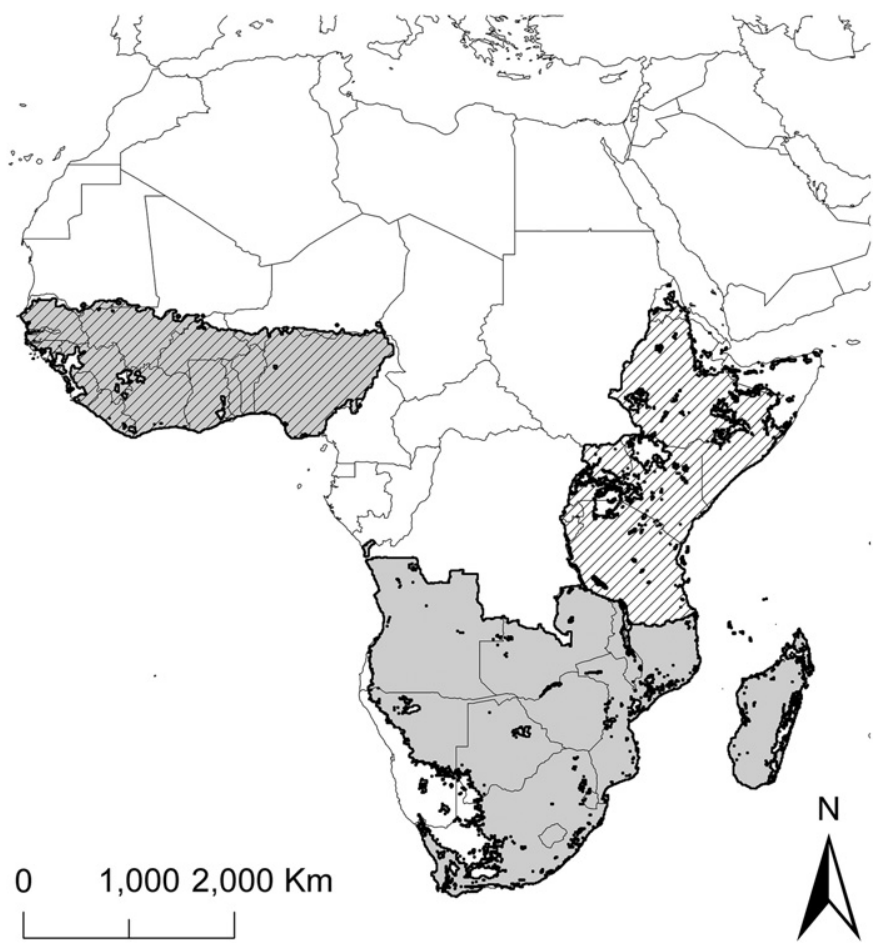

Fig. 2. Map with regions addressed in this study. The gaps occur because a mask was applied eliminating all pixels with NDVI $<0.2$ or $>0.7$ or where the coefficient of variation of NDVI was $<0.1$.

vegetation index phenology indicators: DJF - December, January, February; MAM - March, April, May; JJA - June, July, August; and SON - September, October, November. This aggregation is routinely done by climate organizations instead of more complicated and non-linear smoothing routines. The seasonal averages of the climate indices were then correlated with the annual phenology metrics for cycle 1 and cycle 2 (Fig. 3 ) to capture the effect of the index during each season on the annual phenology metrics for the same year as the index aggregation and on the previous and next year, enabling the capturing of as broad a range of impacts as possible for each climate indicator.

We used the non-parametric Spearman rank correlation to determine the strength of the association between the climate indices and the phenological metrics (Lehman \& D'Abrera, 1975). We test under a null

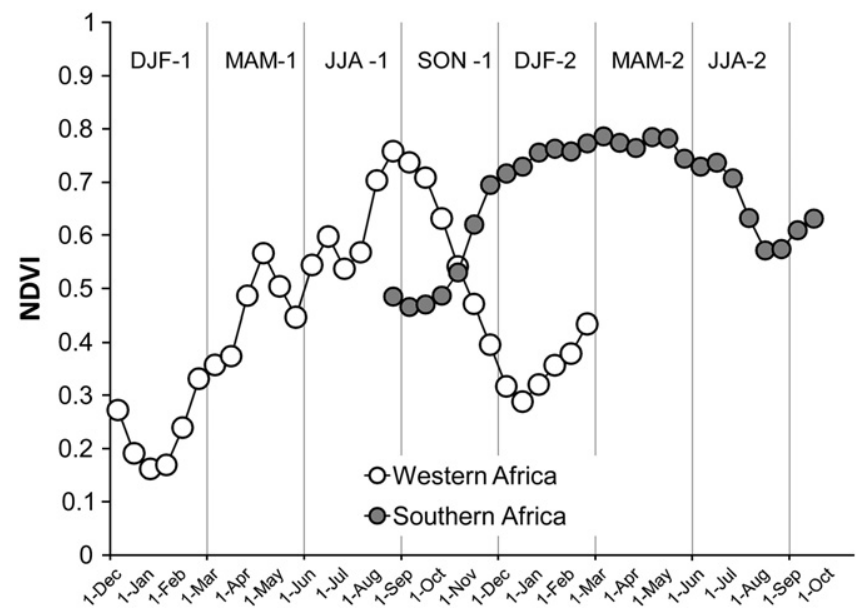

Fig. 3. Two NDVI curves from Western and Southern Africa showing the 2 cycles of analysis, each a year and a half long: cycle 1: October year 1 - March year 3, which captures summer rainy seasons which occur north of the equator, and cycle 2: April year $2-$ October year 3 , which captures winter rainy seasons, such as are prevalent south of the equator.

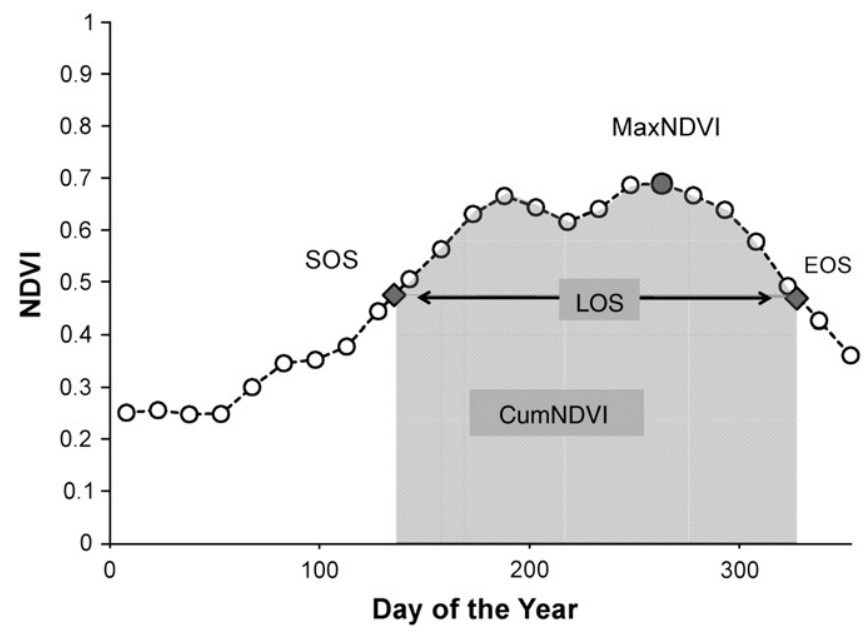

Fig. 4. Phenology metrics using the threshold method, indicating the start of season (SOS), length of season (LOS), date of maximum NDVI of the season (maxNDVI), the date of the end of season (EOS), and the cumulated NDVI over the season (cumNDVI). In this paper, we focus on the impact of climate variability on the SOS and cumNDVI.

hypothesis $\left(\mathrm{H}_{0}\right)$ that there is no correlation $(\rho=0)$ between the phenological metric and the climate index $(n=24$ years) and an alternative hypothesis $\left(\mathrm{H}_{1}\right)$ that the phenological metric and the climate index are correlated $(\rho \neq 0)$. The Spearman rank correlation coefficient is based on the ranked values of the variables rather than on the values themselves as in the common Pearson correlation coefficient. The Spearman correlation makes no assumption with respect to the underlying frequency of the variables and does not presume the variables to be linearly related. Since theoretical studies have shown that the interaction between vegetation and atmosphere is non-linear (e.g. (Bonan, 2002), these are important considerations. If the interaction were indeed non-linear, the Pearson correlation coefficient or simple linear regression could either over or under estimate the strength of the relation (de Beurs \& Henebry, 2008).

\subsection{Statistical analysis}

The results were summarized into the three regions of interest where the NDVI has the strongest correlation to production in semiarid zones: Eastern, Southern and Western Africa (Fig. 2). We focus on these regions because of their long-standing analytical use in the agriculture and famine early warning community (Brown, 2008). Our main goal is to understand if a particular climate mode index is significantly correlated over time with a phenological metrics. In this study we apply the Spearman rank correlation test for every pixel independently. A type I error rate $(\alpha)$ is the probability of wrongly rejecting the null hypothesis. Since we are studying a very large number of pixels ( $n>30,000$ for each region), we have a high probability of finding a certain number of false positives. Consider this example. Were we interested in only a single pixel for which the null hypothesis was true, then the chance that we would find a correlation with a $p$-value lower than 0.01 is very small $(<1 \%)$. Under the null hypothesis of no correlation, the distribution of $p$-values from a large number of Spearman correlation tests is uniform over the interval [0,1] (Fig. 5). Thus, if an $\alpha$ level of 0.1 is chosen as a cutoff, for any given experiment, one of ten $p$-values could be 0.1 or less, even when the null hypothesis is true (Hung et al., 1997). If we perform a correlation test for 100 independent pixels for which the null hypothesis is true, then the chance that we will find at least one pixel with a significant correlation $(p<0.1)$, can be calculated as one minus the chance that there are no significant correlations:

$1-(1-\alpha)^{n}$ 
A

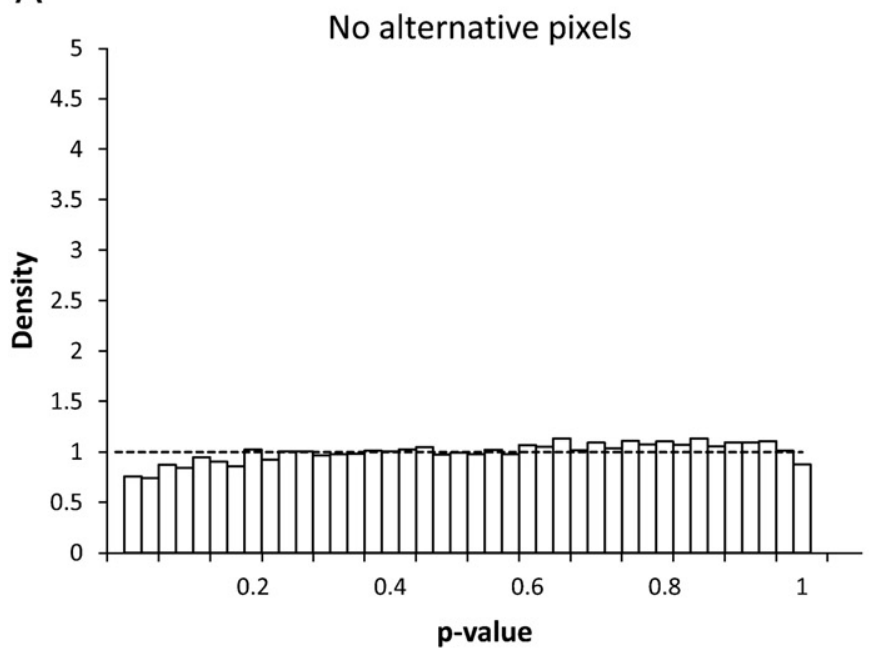

C

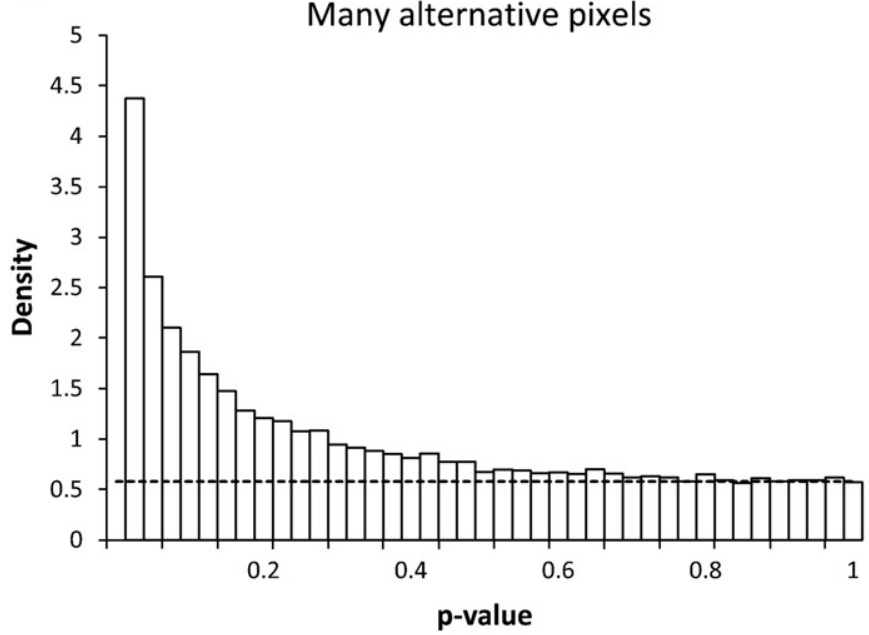

B

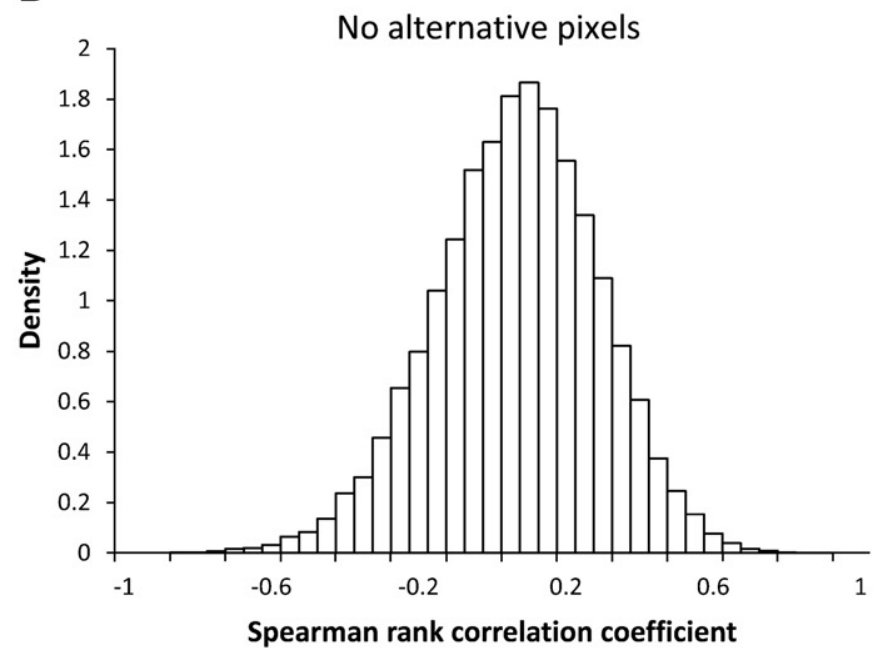

D

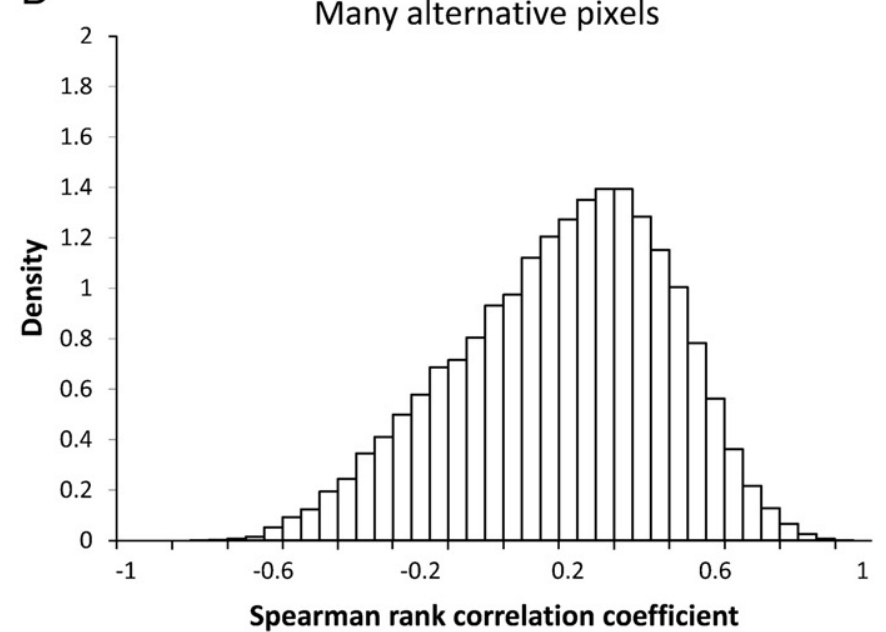

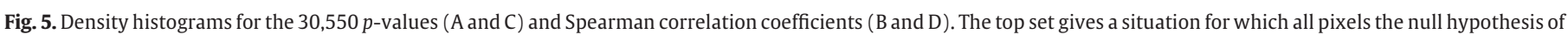

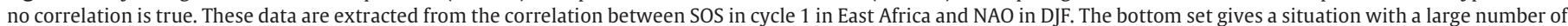

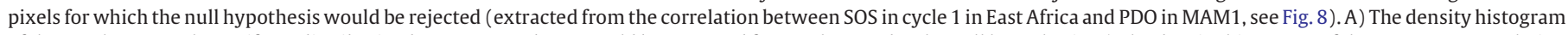

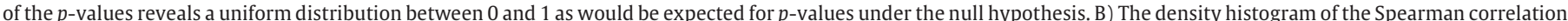

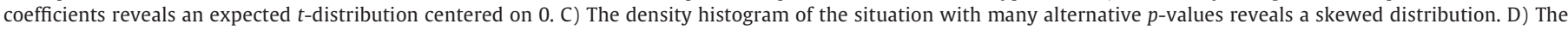

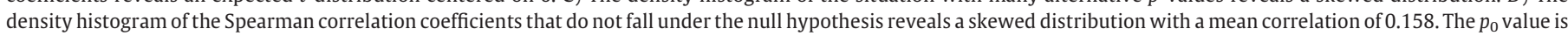

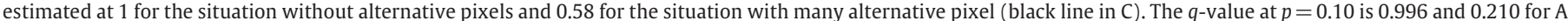
and $C$ respectively.

where $\alpha$ is the significance level and $n$ is the number of tests. Thus, if $\alpha=0.1$, we get $1-(1-0.1)^{100}=0.9997$.

While the probability that a particular pixel would be significantly correlated under the null hypothesis is still very unlikely (e.g., $<10 \%$ ), we have a $99.9 \%$ chance to find at least one significant correlation among 100 pixels for which the null hypothesis of no correlation is true. Thus the family-wise error rate, which is the probability of making one or more false discoveries among all hypotheses when performing multiple tests, is inflated nearly to unity.

A classic method to control the family-wise error rate is by applying the Bonferroni correction. To control the family-wise error rate in multiple comparisons, the Bonferroni correction increases the stringency of the test by normalizing the $p$-value by the number of tests; thus, under the Bonferroni correction, the alternative hypothesis would be rejected for each pixel only if the $p$-value is less than $0.1 / n$. If $n$ is 100 , we would only reject $H_{0}$ for a particular pixel if $p<0.001$. If $n$ is 1000 or more such as is common in our imagery, to keep the family-wise error rate at 0.1 , we would have to only reject $\mathrm{H}_{0}$ for a particular pixel if $p<0.0001$ or less. While such a strict rejection criterion may be desirable in certain cases, the Bonferroni correction is too conservative where $n$ is very large or if there is a certain dependency between pixels. Spatial dependence among residuals makes the Bonferroni correction inefficient.

Over the past few years, microarray technologies have developed to the point where thousands of genes can be measured simultaneously. Different methods have been developed to control error rates that are less stringent than the family-wise error rate. In exploratory data analysis, such as the study presented here, the false discovery rate (FDR) is preferred to the family-wise error rate. The $q$-value gives the minimum FDR that can be retained when calling a specific feature significant (Benjamini \& Hochberg, 1995) or, in other words, it gives the expected proportion of false positives incurred when calling a specific feature significant. The $q$-value is an appropriate measure of significance in situations where a well-defined hypothesis test is performed on thousands of features at the same time (Storey \& Tibshirani, 2003). For each period we calculate the $q$-value that is found for $p=0.1$; thus, $q$ gives the expected proportion of false positives encountered when labeling every pixel with $p \leq 0.1$ as 
significant (Storey \& Tibshirani, 2003). In addition we calculate $1-p_{0}$, where $p_{0}$ is defined as the overall proportion of true null features (pixels lacking correlation/total number of pixels) and is derived from the $p$-value distribution (see Fig. 5 for an example). Thus $1-p_{0}$ gives the proportion of pixels that behaved differently than expected from the null hypothesis (Storey \& Tibshirani, 2003).

In this study, we report the seasonal period with the strongest significance for each climate index and each region. For each index, we reveal the time period with the highest $1-p_{0}$ and report the $q$ value at $p=0.1$ (Storey \& Tibshirani, 2003). We also provide maps of the regions with most significant positive and negative correlations. Additionally, we provide a confusion matrix that gives the percentage of pixels with a $q$-value of less than $50 \%$. In this way we were able to characterize the overall impact of a particular climate index and its interaction with other indices for a region and therefore its importance on growing conditions during the past 26 years.

\section{Results}

Fig. 6 shows the continent-wide model estimates of the start of season for cycle 1 and cycle 2, and the combined cumulative NDVI. Note that we mask data over the moist tropical evergreen forest in the Democratic Republic of Congo and over deserts, where there is no clear seasonality. Regions with two seasons report start of season dates in both cycle 1 and cycle 2 .

Table 1 summarizes the periods for each region that had the highest proportion of pixels that behave differently from the null hypothesis $\left(1-p_{0}\right)$. Table 2 presents the percentage of pixels with a $q$-value $<50 \%$ for the four metrics for each region. A high value indicates that there are a large number of pixels that behave differently than would be expected under the null hypothesis.

\subsection{Western Africa}

In Western Africa, the MEI in the June-August period had the lowest proportion of pixels that are truly null and thus the highest proportion of pixels that behave differently from the null hypothesis of no correlation $1-p_{0}(15.3 \%)$. If calling all pixels with $p<0.1$ significant (14.5\% of the pixels, Table 1$)$, we expect that $58.5 \%(q)$ of those pixels to be false positives. The cumulative NDVI was most strongly influenced by PDO during the September-November period which coincides with the maximum of the growing season. If we call all pixels with $p<0.1$ significant (20.3\% of the pixels), we expect to find that only $34.6 \%$ of those pixels are false positives. Fig. 7 shows the regions with significant correlations $(p<0.1)$ between SOS and MEI and cumulative NDVI and PDO. The figure reveals a familiar and wellknown north-south division of ecoclimatic regions (Nicholson, 2001).

Table 2 reveals that $5.1 \%$ of the pixels correlated with $\mathrm{MEI}$ in the June-August period have a $q$-value of less than $50 \%$, meaning that for only $5.1 \%$ of the pixels the expected proportion of false positives incurred when calling that pixel significant is less than 50\%. There are virtually no pixels with a significant correlation with MEI and another index simultaneously. The PDO during the September-November period dominates the correlation surface for cumulative NDVI during

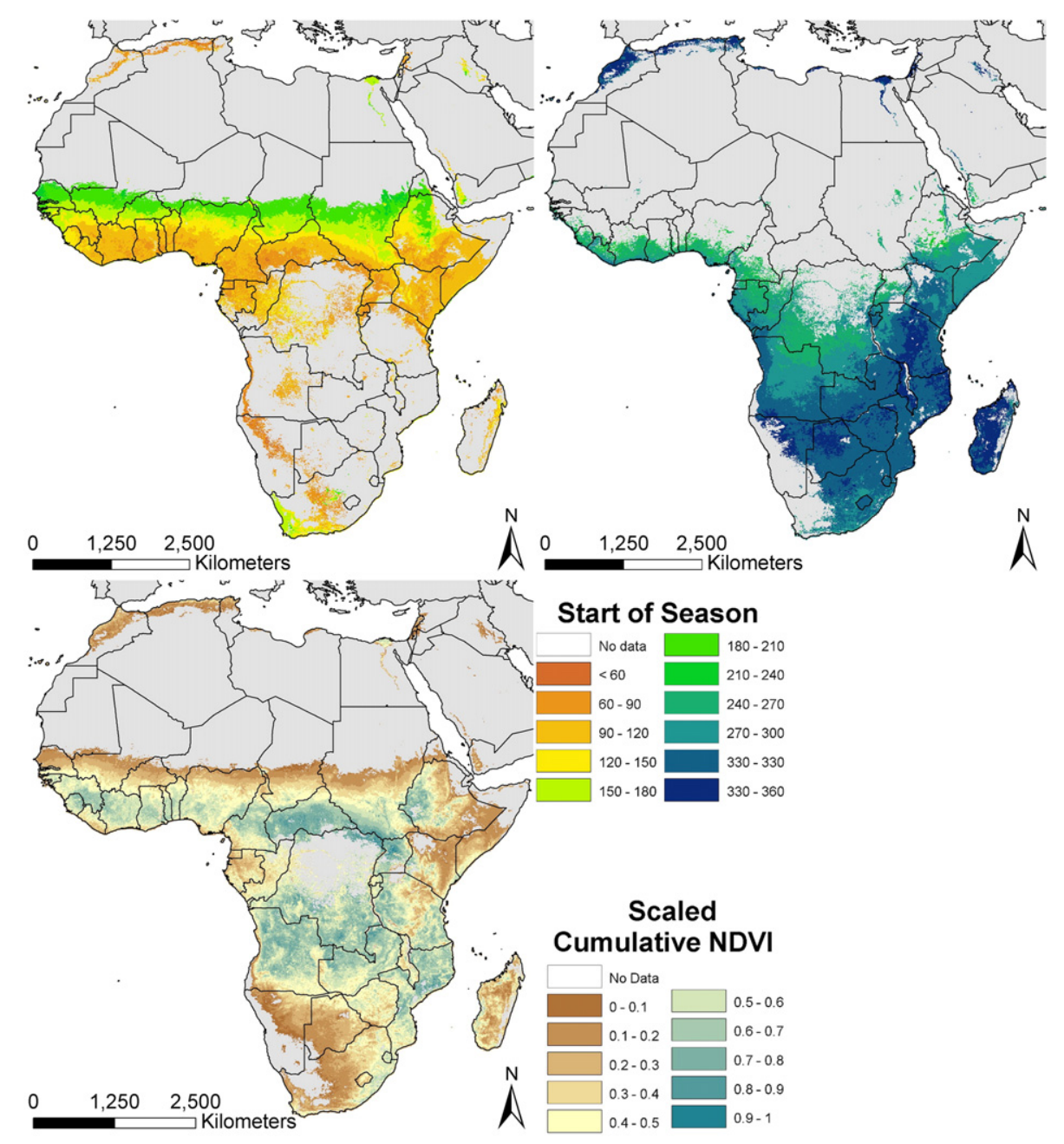

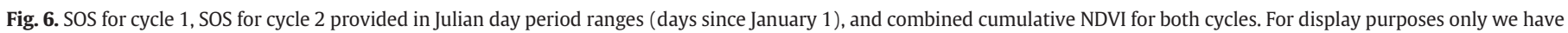
scaled the cumulative NDVI from 0 to 1 by dividing the values by the image maximum. 
Table 1

Results showing the season for each climate index that reveals the highest percentage of pixels that behave differently than expected under the null hypothesis $\left(1-p_{0}\right)$.

\begin{tabular}{|c|c|c|c|c|c|c|c|c|}
\hline & \multicolumn{4}{|c|}{ Start of season } & \multicolumn{4}{|c|}{ Cumulative NDVI } \\
\hline & Period & \% Sig & $q$ & $1-p_{0}$ & Period & $\%$ Sig & $q$ & $1-p_{0}$ \\
\hline \multicolumn{9}{|c|}{ Western Africa -cycle 1} \\
\hline NAO & SONO & 11.9 & 79.1 & 5.6 & SON1 & 11.0 & 83.2 & 6.6 \\
\hline PDO & DJF1 & 13.0 & 70.9 & 7.7 & SON1 & 20.3 & 34.6 & 29.8 \\
\hline MEI & JJA1 & 14.5 & 58.5 & 15.3 & MAM1 & 10.7 & 90.9 & 2.5 \\
\hline IOD & SONO & 11.9 & 81.3 & 3 & MAM1 & 12.4 & 74.3 & 2.7 \\
\hline \multicolumn{9}{|c|}{ Eastern Africa - cycle 1} \\
\hline NAO & JJA1 & 13.2 & 67.7 & 10.6 & JJA1 & 10.6 & 88.8 & 4.6 \\
\hline PDO & MAM1 & 27.5 & 21.0 & 42.1 & SON1 & 14.7 & 61.0 & 9.8 \\
\hline MEI & JJAO & 14.3 & 58.5 & 16.0 & SON1 & 10.6 & 87.5 & 6.4 \\
\hline IOD & JJA0 & 13.3 & 64.7 & 14.1 & DJF1 & 10.3 & 93.2 & 3.2 \\
\hline \multicolumn{9}{|c|}{ Eastern Africa - cycle 2} \\
\hline NAO & MAM2 & 14.3 & 61.9 & 11.6 & MAM2 & 17.0 & 51.6 & 12.5 \\
\hline PDO & DJF2 & 18.6 & 42.0 & 21.9 & MAM1 & 11.2 & 79.3 & 10.1 \\
\hline MEI & SON1 & 15.8 & 48.2 & 23.7 & MAM2 & 19.8 & 37.0 & 26.8 \\
\hline IOD & SON1 & 12.4 & 70.3 & 12.6 & SON1 & 16.1 & 49.1 & 20.8 \\
\hline \multicolumn{9}{|c|}{ Southern Africa - cycle 2} \\
\hline NAO & SON1 & 18.9 & 37.5 & 28.9 & SON2 & 14.1 & 58.7 & 17.0 \\
\hline PDO & DJF2 & 17.8 & 56.3 & 16.5 & JJA2 & 11.3 & 82.0 & 7.3 \\
\hline MEI & SON1 & 16.4 & 49.3 & 19.2 & MAM2 & 20.2 & 37.9 & 23.4 \\
\hline IOD & JJA1 & 14.8 & 56.5 & 16.1 & $\begin{array}{l}\text { All } 1-p 0 \\
\text { values are } 0\end{array}$ & & & \\
\hline
\end{tabular}

$\% \operatorname{Sig}=\%$ of significant pixels with a $p$-value $\leq 0.1$.

$q=$ the $q$-value that is found for $p=0.1$. This indicates that if we call a pixel with $p=0.1$ significant we may expect $q \%$ of those pixels to be false positives.

$p_{0}=$ a conservation estimate of the overall proportion of true null features (pixels without correlation/total number of pixels). Following Storey and Tibshirani (2003) we can say that at least $1-p_{0}$ of the examined pixels behaves differently from the null hypothesis of no correlation. For each index we reveal the time period with the lowest $p 0$. Items in bold refer to those regions with lowest $p_{0}$ by region that we will investigate further.

the growing season, with almost $50 \%$ of the pixels having a $q$-value less than $50 \%$. Virtually no pixels are correlated with PDO and another climate index simultaneously.

\subsection{Eastern Africa}

Cycle 1 in Eastern Africa is especially sensitive to the PDO index in March-May for SOS $\left(1-p_{0}=42.1 \%\right)$. This growing season captures

Table 2

Percentage of pixels that have a $q$-value of less than $50 \%$.

\begin{tabular}{|c|c|c|c|c|c|c|c|c|c|}
\hline & \multicolumn{4}{|c|}{ Start of season } & & \multicolumn{4}{|c|}{ Cumulative NDVI } \\
\hline & NAO & PDO & MEI & IOD & & NAO & PDO & MEI & IOD \\
\hline \multicolumn{10}{|c|}{ Western Africa - cycle 1} \\
\hline NAO-SONO & 0.1 & $<0.1$ & $<0.1$ & $<0.1$ & SON1 & $<0.1$ & $<0.1$ & $<0.1$ & $<0.1$ \\
\hline PDO-DJF 1 & & 2.0 & $<0.1$ & $<0.1$ & SON1 & & 49.7 & $<0.1$ & $<0.1$ \\
\hline MEI-JJA 1 & & & 5.1 & $<0.1$ & MAM1 & & & $\mathbf{0}$ & $<0.1$ \\
\hline IOD-SONO & & & & 0.4 & MAM1 & & & & 2.0 \\
\hline \multicolumn{10}{|c|}{ Eastern Africa - cycle 1} \\
\hline NAO-JJA1 & 0.6 & 0.5 & $<0.1$ & $<0.1$ & JJA1 & 0.2 & $<0.1$ & $<0.1$ & $<0.1$ \\
\hline PDO-MAM1 & & 82.7 & 4.2 & 1.6 & SON1 & & 7.7 & $<0.1$ & $<0.1$ \\
\hline MEI-JJA0 & & & 4.6 & 0.5 & SON1 & & & 0.2 & $<0.1$ \\
\hline IOD-JJAO & & & & 2.1 & DJF1 & & & & $<0.1$ \\
\hline \multicolumn{10}{|c|}{ Eastern Africa - cycle 2} \\
\hline NAO-MAM 2 & 4.2 & 1.1 & 1.1 & 0.9 & MAM2 & 15.3 & $<0.1$ & 7.1 & 4.4 \\
\hline PDO-DJF 2 & & 27.7 & 8.7 & $<0.1$ & MAM1 & & $<0.1$ & $<0.1$ & $<0.1$ \\
\hline MEI-SON 1 & & & 20.1 & $<0.1$ & MAM2 & & & 40.1 & 11.3 \\
\hline IOD-SON 1 & & & & 0.1 & SON1 & & & & 18.0 \\
\hline \multicolumn{10}{|c|}{ Southern Africa - cycle 2} \\
\hline NAO-SON1 & 43.7 & 2.1 & 7.5 & 2.6 & SON2 & 4.1 & $<0.1$ & 2.1 & $<0.1$ \\
\hline PDO-DJF2 & & 6.2 & 2.8 & 0.6 & JJA2 & & 0.2 & 0.1 & $<0.1$ \\
\hline MEI-SON1 & & & 17.5 & 3.2 & MAM2 & & & 35.2 & $<0.1$ \\
\hline IOD-JJA1 & & & & 6.4 & none & & & & $<0.1$ \\
\hline
\end{tabular}

the main rainy season, which in Ethiopia is called 'meher' and runs from June to October. Ethiopia produces $90-95 \%$ of its total cereal output during the main meher season (PECAD, 2002). Interestingly, while the effect of PDO is strong on the start of season, it is less relevant for the cumulative NDVI $\left(1-p_{0}=9.8 \%\right)$. Table 2 also shows that the cycle 1 (summer) season in East Africa is dominated by the PDO in March-May, with $82.7 \%$ of the pixels with a $q$-value less than $50 \%$. Most pixels with correlation with other indices also are significant with the PDO (e.g. for MEI $4.6 \%$ of the pixels have a $q$-value less than $50 \%$ but almost all those pixels, i.e. $4.2 \%$, are also captured by PDO). Fig. 8 shows the spatial distribution of the correlation between SOS and PDO in March-May and between cumulative NDVI and PDO in September-November. Large areas of significant positive correlation are found in the Ethiopian-Sudan border area, eastern Ethiopia, southern Somalia, and large parts of Kenya. It is interesting to see north-south region of significant negative correlation in the higher elevation areas of central Ethiopia.

The cycle 2 results capture the Ethiopian 'belg' season, the Somalian 'gu' season, and Kenya's 'long rains' between February and June. Both the PDO index in the period December-February and the MEI index from September-November in the previous year influence SOS ( $1-p_{0}$ are $21.9 \%$ and $23.7 \%$ respectively). Cumulative NDVI in the region is particularly influenced by MEI in March-May. Table 2 confirms the influence of both PDO and MEI on the SOS in cycle 2; $27.7 \%$ of the pixels with PDO from December-February have a $q$-value $<50 \%$ while $20.1 \%$ of the pixels are correlated with the MEI from September-November with a $q$-value $<50 \%$. Note, however that only $8.7 \%$ of the pixels are correlated with both indices simultaneously. Analysis shows that the majority of the correlations occur at different pixel locations, and thus the interaction between climate indices is small. Fig. 8 shows the pixels with positive and negative correlations with the PDO for cycle 1 and MEI for cycle 2, the two periods with the most widespread significant correlations.

\subsection{Southern Africa}

In Southern Africa we found that all climate indices correlated with one or more of the phenology metrics at some period of the year. Start of season during cycle 2 was most influenced by the NAO during the September-November period $\left(1-p_{0}\right.$ value of $\left.28.9 \%\right)$. The cumulative NDVI was most influenced by the MEI $\left(1-p_{0}\right.$ value of $\left.23.4 \%\right)$ and $20.2 \%$ of pixels having a significant relationship ( $p$-value $<0.1$ ) to the index during March-May period. The NAO and MEI are the dominating modes affecting the start of season in Southern Africa, with $43.7 \%$ and $17.5 \%$ of the pixels significantly affected with a $q$-value of less than $50 \%$. Only $7.5 \%$ of the pixels are affected by both modes simultaneously. For the cumulative NDVI, MEI in the second March-May period is the dominating mode. There, $35.2 \%$ of the pixels reveal correlation with MEI in the second March-May period with a $q$-value lower than $50 \%$. Fig. 9A,B shows the regions with positive and negative correlations at $p<0.1$. Note that for both the start of season and the cumulative NDVI, the effect of the climate indices is negative, with a delayed start and lower cumulative NDVI than average for high index values.

\section{Discussion}

The results of this paper highlight climate-vegetation relationships that could be very valuable for the analysis of seasonal variation in the climate in Africa. The relationships are evidence of recurring and persistent, large scale patterns of pressure and circulation anomalies that span vast geographical areas. We show that seasonal phenological patterns as derived from the 26 year vegetation index record can be used to estimate the importance or lack of importance of four large scale climate oscillations on vegetation in Western, Eastern and Southern Africa. 




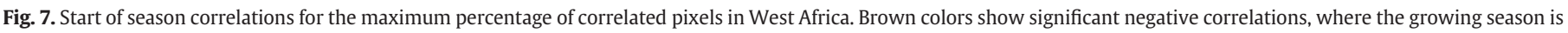

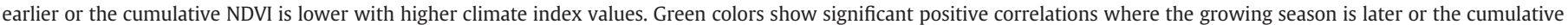
NDVI is higher with higher climate index values or vice versa. Underlying image is the combined cumulative NDVI for both cycles.

The GIMMS NDVI dataset is not perfect as a source of information on agricultural productivity or characteristics. Here we use a phenology model to transform the bimonthly NDVI dataset into phenological parameters. Previous research and extensive use of GIMMS NDVI and phenology metrics in Africa has shown that the start of season and cumulative NDVI are the most stable and reliable parameters, with the longest record of use and publications in Africa (Brown \& de Beurs, 2008; Tucker et al., 2005). Our interest is to understand the impact of climate variability on growing season quality, as measured by phenological parameters and we are able to move significantly closer to understanding the impact of climate variability on agriculture.

The start of season is particularly important for determining yields in a given season, since in many semi-arid areas, the length of the growing season is an important determinant of yield. If the season begins late, the likelihood of average yields declines significantly (FEWS, 1992; Groten \& Ocatre, 2002; Verdin et al., 2000). Thus negative correlations (implying a later start for lower index values) with SOS over the 26 year NDVI record is an important estimate of the impact of the climate oscillation on overall agricultural productivity in that season because in semi-arid zones, a delayed start results in reduced yields. Variations in climate indices can then be used to estimate future changes in growing season length, start and strength based on this research.

The impact of the Pacific Decadal Oscillation on the climate of Africa during the past few decades is unclear, although Rouault (2002) examined the association between the PDO and South African rainfall and noted that the warm (cool) phase of the interdecadal variability in the Pacific and Indian Ocean is associated with decreased (increased) rainfall over South Africa (Reason \& Rouault, 2002). This study has found significant relationships between the PDO and the growing season in both East and West Africa. These relationships are spatially coherent and result in lower growing season productivity in the Sahel, from Senegal through to western Ethiopia. We also see a relationship between the PDO and the MEI metric in Eastern Africa for the second cycle, although the interaction is present in less than $10 \%$ of the pixels.

In Eastern Africa, we found significant correlations between SOS during the second cycle and the MEI metric in the SeptemberNovember period. The maps presented in Fig. 8 show negative relationships in the semi-arid pastoral zone of eastern Ethiopia, Somalia, Kenya, and for much of Tanzania. This region has been experiencing a multi-year drought during the past decade which has resulted in failed harvests, water shortages and deteriorating rangeland conditions (FEWSNET, 2006; Funk et al., 2005). Our results confirm the importance of ENSO on the productivity of the second cycle growing season, for $26.8 \%$ of the pixels in eastern Africa have a significant relationship with MEI, confirming the work of Anyamba et al. (2001). The effect of the global climate system on this region where there are millions of food insecure farmers and pastoralists has been a topic of much recent research.

Our results are confirmed by other authors who have found that Southern Africa is sensitive to both the pacific and ENSO effects (Eastman et al., 1996; Nicholson, 2003; Ropelewski \& Halpert, 1986). In Western Africa the interactions of the metrics tested here show 


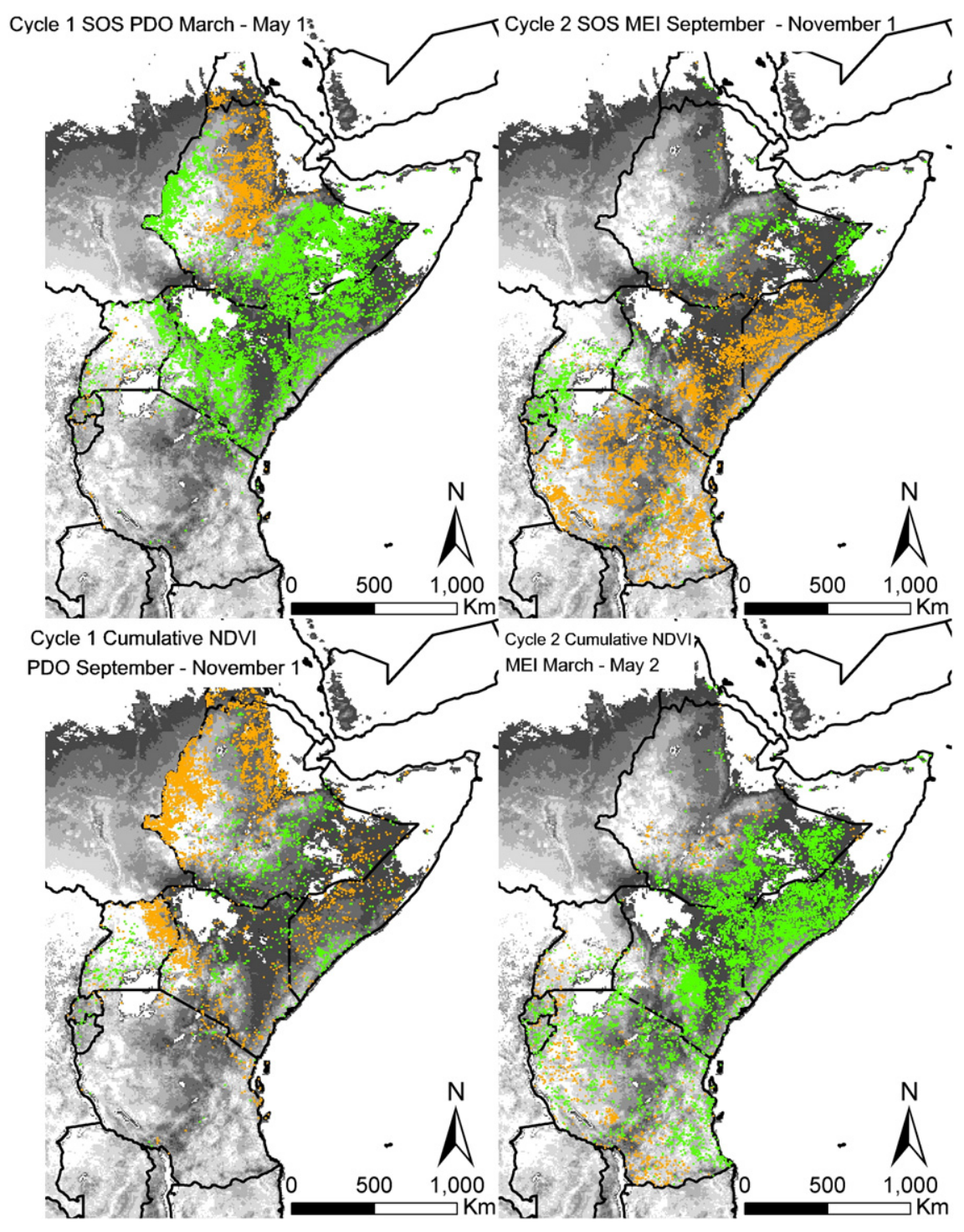

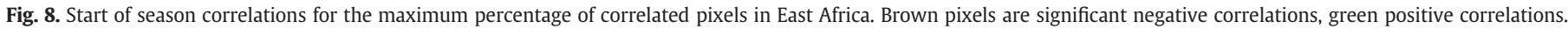
Underlying image is the combined cumulative NDVI for both cycles.

little to no convincing correlation, except for perhaps the MEI, which behaved differently from the null hypothesis of no correlation, 15.3\% of the pixels. Table 2 confirms these results and shows little to no interaction between the metrics.

Future research will focus on the forecasting potential of climatic indices for phenological metrics and thus crop production. Future steps would be to assess the simultaneous impact of multiple climatic indices on the observed phenology events, which are predominately visible in Eastern and Southern Africa. Impacts of different indices could be additive, potentially resulting in increased explanatory power. In addition, our figures show that high correlation exists in sub-regions of Eastern and Southern Africa. Thus, detailed impact studies in sub-regions may be useful as well.

\section{Conclusions}

Given the agricultural nature of most economies on the African continent, agricultural production continues to be a critical determinant of both food security and economic growth (Funk \& Brown, 2009). In this paper, we explore the relationship between large scale climate oscillations and land surface phenology metrics to determine how influential each climate oscillation is on the growing season as recorded by NDVI. Crop phenological parameters, such as the start and end of the growing season, the total length of the growing season, and the rate of greening and senescence are important for planning crop management and crop diversification and intensification. Because these crop parameters are sensitive to climate variability, understanding which climate oscillations are most influential and affect variation in these phenology metrics from one year to the next can improve seasonal analysis and agriculture planning across the continent.

We found that the start of season and cumulative NDVI were significantly affected by variations in the climate oscillations in the three regions examined. Eastern Africa that has been experiencing drought in recent years is particularly sensitive to PDO variations in March-April-May. The growing season in Southern African is sensitive to variations in the ENSO metric MEI, as well as NAO. The IOD was found to have a virtually no influence on phenology in all three regions. The use of current climate indices to estimate variability in the next growing season is the subject of future research, as this could provide the opportunity to forecast agricultural production in the region. 


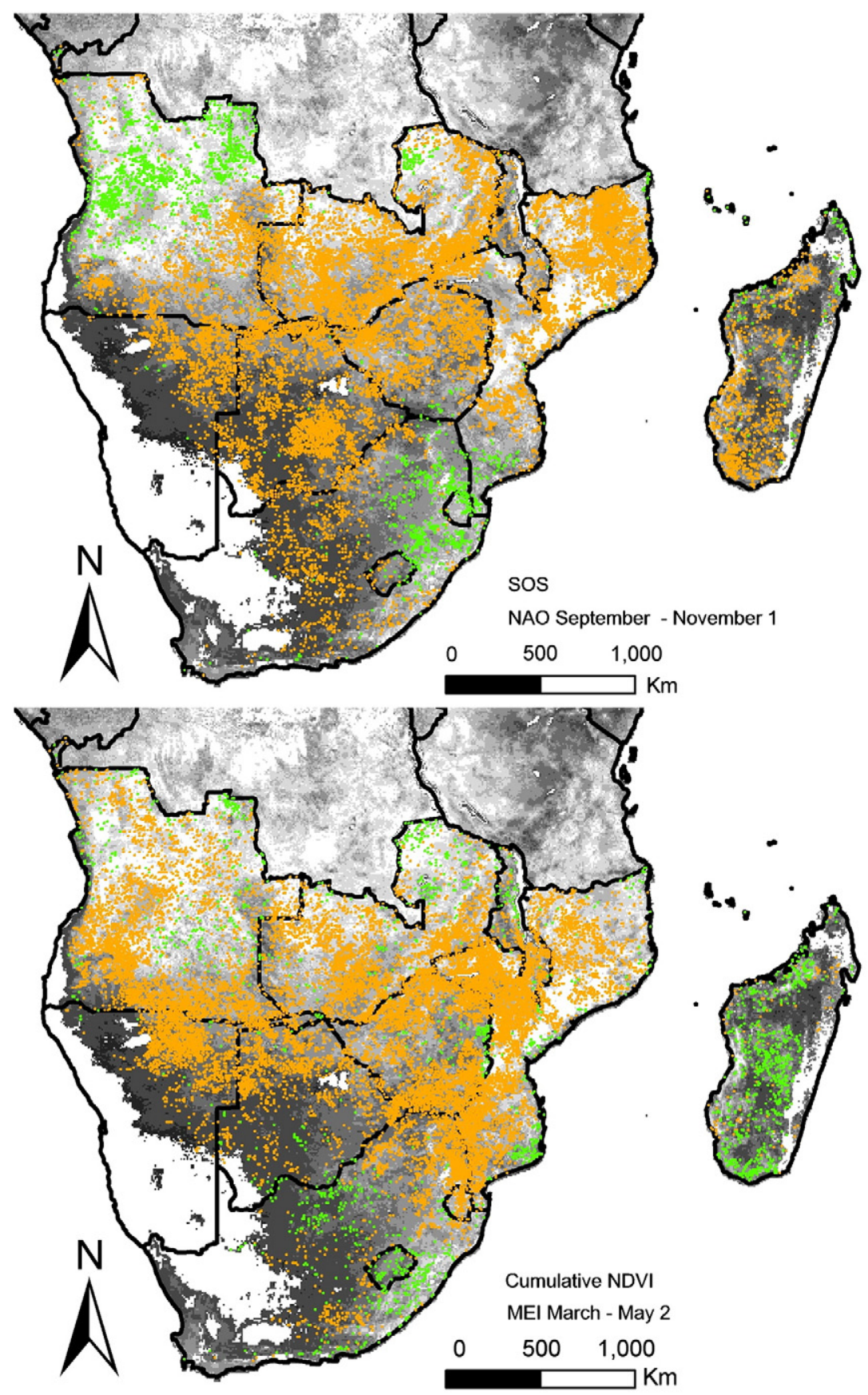

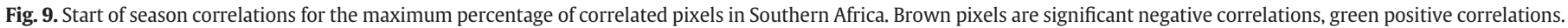
Underlying image is the combined cumulative NDVI for both cycles.

\section{References}

Alberts, B., \& Mehta, G. (2004). Realizing the promise and potential of African agriculture. Amsterdam, The Netherlands: Interacademy Council.

Anyamba, A. (1997). Interannual variations of NDVI over Africa and their relationship to ENSO: 1982-1995. Department of geography. Clark University (p. 132).

Anyamba, A., Tucker, C. J., \& Eastman, J. R. (2001). NDVI anomaly patterns over Africa during the 1997/1998 ENSO warm event. International Journal of Remote Sensing, 22, $1847-1859$.

Awaya, Y Kodani, E Tanaka, K. Liu, J. Zhuang D \& Meng Y (2004). Estimation of the global net primary productivity using NOAA images and meteorological data: Changes between 1988 and 1993. International Journal of Remote Sensing, 25, 1597-1613.

Benjamini, Y., \& Hochberg, Y. (1995). Controlling the false discovery rate: A practical and powerful approach to multiple testing. J R Stat Soc B, 57, 289-300.

Bonan, G. (2002). Ecological climatology. London: Cambridge University Press.

Breman, H. (2003). West Africa's subsistence farming. Rome: Togo: Food and Agriculture Organization (p. 16).
Brown, M. E. (2008). Famine early warning systems and remote sensing data. Heildelberg: Springer Verlag.

Brown, M. E \& de Beurs, K. (2008). Evaluation of multi-sensor semi-arid crop season parameters based on NDVI and rainfall. Remote Sensing of Environment, 112, 2261-2271.

Brown, M. E., Pinzon, J. E., \& Prince, S. D. (2006). The sensitivity of millet prices to vegetation dynamics in the informal markets of Mali, Burkina Faso and Niger. Climatic change, 78, 181-202.

Buerkert, A., Moser, M., Kumar, A. K., Furst, P., \& Becker, K. (2001). Variation in grain quality of pearl millet from Sahelian West Africa. Field Crops Research, 69, 1-11.

Cane, M. A., Clement, A., Kaplan, A., Kushnir, Y., Pozdnyakov, D., Seager, R., et al. (1996). 20th-century sea-surface temperature trends. Science, 275, 957-960.

Chen, J., Jönsson, P., Tamura, M., Gu, Z., Matsushita, B., \& Eklundh, L. (2004). A simple method for reconstructing a high-quality NDVI time-series data set based on the Savitzky-Golay filter. Remote Sensing of Environment, 91, 332-344.

de Beurs, K. M., \& Henebry, G. M. (2008). Northern annular mode effects on the land surface phenologies of Northern Eurasia. Journal of Climate, 21, 4257-4279. 
Eastman, J. R., Anyamba, A., \& Ramachandran, M. (1996). The spatial manifestations of ENSO warm phase events in Southern Africa. Conference on the application of remotely sensed data and geographic information systems in environmental and natural resources assessment in Africa. Zimbabwe: Harare.

Ellsworth, L., \& Shapiro, K. (1989). Seasonality in Burkina Faso grain marketing: farmer strategies and government policy. In D. E. Sahn (Ed.), Seasonal variability in third world agriculture (pp. 196-205). Baltimore: Johns Hopkins University Press.

FAO (2006). The state of food insecurity in the world. Rome, Italy: United Nations Food and Agriculture Organization (p. 30).

FEWS (1992). Determining start of the growing season using Max NDVI. Arlington: VA: FEWS-ARD (p. 18)

FEWS (2008). Food price database at USGS Africa data dissemination service (ADDS). USAID.

FEWSNET (2006). Kenya food security update - December 6, 2006. Washington DC: Famine early warning system network (p. 5).

Funk, C., \& Brown, M. E. (2009). Declining global per capital agricultural capacity and warming oceans threaten food security. Food Security Journal, 1, 271-289.

Funk, C., Sanay, G., Asfaw, A., Korecha, D., Choularton, R., Verdin, J., et al. (2005). Recent drought tendencies in Ethiopia and equatorial-subtropical Eastern Africa. Washington DC: Famine early warning system network, USAID (p. 11).

Funk, C. C., \& Budde, M. E. (2009). Phenologically-tuned MODIS NDVI-based production anomaly estimates for Zimbabwe. Remote Sensing of Environment, 113, 115-125.

Glantz, M. H., Katz, R. W., \& Nicholls, N. (1991). Teleconnections linking world wide climate anomalies: Scientific basis and societal impact. New York: Cambridge University Press.

Green, R. M., \& Hay, S. I. (2002). The potential of Pathfinder AVHRR data for providing surrogate climatic variables across Africa and Europe for epidemiological applications. Remote Sensing of Environment, 79, 166-175.

Groten, S. M. E., \& Ocatre, R. (2002). Monitoring the length of the growing season with NOAA. International Journal of Remote Sensing, 24, 2797-2815.

Holben, B. (1986). Characteristics of maximum-value composite images from temporal AVHRR data. International Journal of Remote Sensing, 7, 1417-1434.

Hung, J. H. M., O'Neill, R. T., Bauer, P., \& Kohne, K. (1997). The behavior of the $p$-value when the alternative hypothesis is true. Biometrics, 53, 11-12.

Hurrell, J. W. (1995). Decadal trends in the North Atlantic Oscillation: Regional temperatures and precipitation. Science, 269, 676-679.

Jones, P. D., Jónsson, T., \& Wheeler, D. (1997). Extension to the North Atlantic Oscillation using early instrumental pressure observations from Gibraltar and South-West Iceland. International Journal of Climatology, 17, 1433-1450.

Jury, M. R., McQueen, C., \& Levey, K. (1994). SO1 and QBO Signals in the African Region. Theoretical and Applied Climatology, 50, 103-115.

Justice, C. O., Townshend, J. R. G., Holben, B. N., \& Tucker, C. J. (1985). Analysis of the phenology of global vegetation using meteorological satellite data. International Journal of Remote Sensing, 6, 1271-1318.

Lehman, E. L., \& D'Abrera, H. J. M. (1975). Nonpara-metrics-statistical methods based on ranks. San Francisco, CA: Holden-Day.

Lotsch, A., Friedl, M. A., Anderson, B. T., \& Tucker, C. J. (2003). Coupled vegetationprecipitation variability observed from satellite and climate records. Geophysical Research Letters, 30.

Mantua, N. J., \& Hare, S. R. (2002). The Pacific Decadal Oscillation. Journal of Oceanography, $58,35-44$.

Mantua, N. J., Hare, S. R., Zhang, Y., Wallace, J. M., \& Francis, R. C. (1997). A Pacific interdecadal climate oscillation with impacts on salmon production. Bulletin of the American Meteorological Society, 78, 1069-1079.

McCabe, G. J., Palecki, M. A., \& Betancourt, J. L. (2004). Pacific and Atlantic Ocean influences on multidecadal drought frequency in the United States. Proceedings of the National Academy of Science, 101, 4136-4141.

Nicholson, S. (2003). The South Indian convergence zone and interannual rainfall variability over Southern Africa and the question of ENSO's influence on Southern Africa. Journal of Climate, 16, 555-562.

Nicholson, S. E. (2001). Climatic and environmental change in Africa during the last two centuries. Climate Research, 17, 123-144.

Parry, M. L., Canziani, O. F., Palutikof, J. P., Linden, P. J.v. d., \& Hanson, C. E. (Eds.). (2007) IPCC, 2007: Climate change 2007: Impacts, adaptation and vulnerability. Contribution of working group II to the fourth assessment report of the intergovernmental panel on climate change. Cambridge, UK: Cambridge University Press.

PECAD (2002). Ethiopia: Drought intensifies during corn and sorghum harvest. Production estimates and crop assessments. USDA Foreign Agricultural Service: Washington DC.

Pinzon, J., Brown, M. E., \& Tucker, C. J. (2005). Satellite time series correction of orbital drift artifacts using empirical mode decomposition. In N. Huang (Ed.), Hilbert-Huang transform: Introduction and applications (pp. 167-186).

Rasmussen, E. (1991). Observational aspects of ENSO cycle teleconnections. In M. Glantz, \& N. Nicholls (Eds.), Teleconnections linking worldwide climate anomalies (pp. 309-344). Cambridge University Press.

Rasmusson, E. M., \& Wallace, J. M. (1983). Meteorological aspects of the El Niño/Southern Oscillation. Science, 222, 1195-1202.

Reason, C. J. C., \& Rouault, M. (2002). ENSO-like decadal variability and South African rainfall. Geophysical Research Letters, 29. doi:10.1029/ 2002GL014663, 014616-014661-014664.

Ropelewski, C. F., \& Halpert, M. S. (1986). Global and regional scale precipitation patterns associated with the El Nino/Southern Oscillation. Monthly Weather Review, $115,1606-1626$.

Ropelewski, C. F., \& Halpert, M. S. (1987). Global and regional scale precipitation patterns associated with the El Nino/Southern Oscillation. Monthly Weather Review, $115,1606-1626$.

Sacks, W. J., Deryng, D., Foley, J. A., \& Ramankutty, N. (in press). Crop planting dates: An analysis of global patterns. Global Ecology and Biogeography.

Saji, N., Goswami, B., \& Yamagata, T. (1999). A dipole mode in the tropical Indian Ocean. Nature, 401, 360-363.

Storey, J. D., \& Tibshirani, R. (2003). Statistical significance for genomewide studies. Proceedings of the National Academy of Sciences, 100, 9440-9445.

Thompson, D. W., \& Wallace, J. M. (2001). Regional climate impacts of the northern hemisphere annular mode. Science, 293, 85-89.

Tucker, C. J., Pinzon, J. E., Brown, M. E., Slayback, D., Pak, E. W., Mahoney, R., et al. (2005). An extended AVHRR 8-km NDVI data set compatible with MODIS and SPOT vegetation NDVI data. International Journal of Remote Sensing, 26, 4485-4498.

UCAR (2009). Persistent patterns that shape weather and climate variability-A glossary. In B. H. Kevin Trenberth, \& Zhenya Gallon (Eds.), Backgrounders. Boulder: CO: NCAR/ UCAR.

USAID (2007). The history of America's food aid. US State Department.

Vasagar, J. (2005). Plenty of food - Yet the poor are starving. Guardian (UK). Niger: TAHOUA

Verdin, J., Funk, C., Kalver, R., \& Roberts, D. (1999). Exploring the correlation between Southern Africa NDVI and Pacific sea surface temperatures: Results for the 1998 Maize growing season. International Journal of Remote Sensing, 20, 2117-2124.

Verdin, J., Lietzow, R., Rowland, J., Klaver, R., Reed, B., French, V., et al. (2000). A comparison of methods for estimating start-of-season from operational remote sensing products: First results. Sioux Falls. SD: USGS-EROS Data Center (p. 13).

Vrieling, A., de Beurs, K. M., \& Brown, M. E. (2008). Recent trends in agricultural production of Africa based on AVHRR NDVI time series. Proceedings of SPIE - The international society for optical engineering (pp. 71040R).

Wang, G. (2003). Reassessing the impact of North Atlantic Oscillation on the sub-Saharan vegetation production. Global Change Biology, 9, 493-499.

White, M. A., Thornton, P. E., \& Running, S. W. (1997). A continental phenology mode for monitoring vegetation responses to interannual climatic variability. Globa Biogeochemical Cycles, 11, 217-234.

Williams, C. A., Hanan, N. P., Baker, I., Collatz, G. J., Berry, J. A., \& Denning, A. S. (2008) Interannual variability of photosynthesis across Africa and its attribution. Journal of Geophysical Research-Atmospheres, 113, G04015.

Wolter, K., \& Timlin, M. S. (1998). Measuring the strength of ENSO - how does 1997/98 rank? Weather, 53, 315-324.

Woodward, F. I., Lomas, M. R., \& Quaife, T. (2008). Global responses of terrestrial productivity to contemporary climatic oscillations. Philosophical transactions of the royal society $B, 363,2779-2785$.

Zhang, X., Friedl, M. A., Schaff, C. B., Strahler, A. H., \& Liu, Z. (2005). Monitoring the response of vegetation phenology to precipitation in Africa by coupling MODIS and TRMM instruments. Journal of Geophysical Research-Atmospheres, 110, D12103. 